MATEC Web of Conferences 19,01031 (2014)

DOI: $10.1051 /$ matecconf/ 20141901031

(C) Owned by the authors, published by EDP Sciences, 2014

\title{
PHYSICAL BASIS OF POWER TRANSMISSION WIRE'S DEICING BY ELECTRODYNAMIC METHOD
}

\author{
Danil Yu. Lyapunov $^{\mathrm{a}^{*}}$, Sergey.I. Sukhorukov ${ }^{* *}$, Vyacheslav.A. Soloviev ${ }^{* *}$ and Victor.M. Kozin ${ }^{* *}$ \\ *National Research Tomsk Polytechnic University, 634050 Tomsk, Russia \\ ${ }^{* *}$ Komsomolsk-na-Amure State Technical University, 681013 Komsomolsk-na-Amure, Russia
}

\begin{abstract}
In this paper a new method of power transmission wire's deicing is described. Deicing process is divided into three independent sub-processes, namely the process of melting the thin inner layer of ice cover, the process of ice cylinder fracturing into components due to bending deformations; the process of shaking off the fractured ice cylinder elements by inertial forces. Mathematical description of each sub-process is shown.
\end{abstract}

\section{Introduction}

In $[1,2]$ a method of power transmission wire's deicing, based on the use of the electrodynamic and thermal influences on the wires, is described. Thus, a controllable source of current, generating pulses of a specific frequency, duty cycle and amplitude, is proposed to use as the source of both effects [3]. As a result of these impacts ice cover will be exposed to heating of the inner layer, the bending deformation of the forced vibrations of the wire in the span between the tangent towers, and the impact from shaking the wire.

If we assume that the deicing process is linear, then, based on the principle of superposition, it can be conditionally divided into three independent sub-processes: the process of thin inner layer melting of ice cover, which provides a sharp decrease in the adhesive properties of the contact "wire-ice"; the process of ice cylinder fracturing into components due to bending deformations; the process of shaking off the fractured ice cylinder elements by inertial forces.

The purpose of present work is creating of mathematical description for each of the sub-processes mentioned above.

\section{Process of thin inner layer melting of ice cover}

In considering the sub-process, the next assumptions were introduced:

- Ice cover has the shape of an ideal cylinder having an inner diameter determined by the wire section and the outer diameter - by the thickness of deposited ice.

- The density of ice is uniform and the structure of ice is constant.

- Conductor stranded cable in cross-section is a perfect circle and has no release coating.

- The temperature of the ice cover and the temperature of the cable are the same.

${ }^{\text {a }}$ Corresponding author: lyapunov@tpu.ru

This is an Open Access article distributed under the terms of the Creative Commons Attribution License 4.0, which permits unrestricted use, distribution, and reproduction in any medium, provided the original work is properly cited. 


\section{MATEC Web of Conferences}

- Heat capacity of supporting steel core is equal to the heat capacity of aluminum wire.

In $[4,5]$ experimental data on the adhesion strength of contact "ice-material" are shown. The data show dependence of the adhesion strength on the contact's temperature, physical-mechanical properties of ice and a number of other characteristic. It's shown, that the adhesion strength sharply decreases then the thin water layer occurs between ice and material. Therefore, the main task of the sub-process is the formation of a reliable water layer.

With the assumptions above, the energy required for creating the water layer can be defined as:

$$
W_{w . l}=W_{h . c}+W_{i c e},
$$

where: $W_{h . c}$ - energy required for heating cable $(\mathrm{J}) ; W_{\text {ice }}$ - energy required for conversion ice to other aggregate state $(\mathrm{J})$.

$$
W_{h . c}=c_{c} \cdot m_{c} \cdot\left(t_{1}-t_{2}\right)=c_{c} \cdot l \cdot\left(\rho_{s t} \cdot s_{s t}+\rho_{a l} \cdot s_{a l}\right) \cdot\left(t_{1}-t_{2}\right),
$$

where: $c_{c}$ - heat capacity of the cable $(920 \mathrm{~J} /(\mathrm{kg} \cdot \mathrm{K})) ; m_{c}$ - cable's mass $(\mathrm{kg}) ; t_{1}$ - temperature of heated cable $\left({ }^{\circ} \mathrm{C}\right) ; t_{2}$ - initial temperature of a contact "wire-ice" $\left({ }^{\circ} \mathrm{C}\right) ; l$ - length of span $(\mathrm{m}) ; \rho_{s t}-$ density of steel core $\left(\mathrm{kg} / \mathrm{m}^{3}\right) ; \rho_{a l}$ - density of aluminium wire $\left(\mathrm{kg} / \mathrm{m}^{3}\right) ; s_{s t}$ - total cross section of steel core $\left(\mathrm{m}^{2}\right) ; s_{a l}-$ total cross section of aluminium wire $\left(\mathrm{m}^{2}\right)$. To simplify the calculation of the mass of wire, hanged in the span, we use the reference data [6].

$$
W_{\text {ice }}=c_{\text {ice }} \cdot m_{i . l} \cdot\left(0-t_{2}\right)+q_{m . i} \cdot m_{\text {ice }}+c_{w} \cdot m_{w} \cdot\left(t_{1}-0\right),
$$

where: $c_{i c e}$ - specific heat capacity of ice $(2110 \mathrm{~J} /(\mathrm{kg} \cdot \mathrm{K})) ; m_{i . l}=\rho_{i c e} \cdot l \cdot \pi \cdot \Delta d_{m} \cdot\left(d+\Delta d_{m}\right)-$ mass of ice, which should be melted (kg); $q_{m . i}$ - specific heat of ice melting $(330000 \mathrm{~J} / \mathrm{kg}) ; c_{w}-$ specific heat of water $(4218 \mathrm{~J} /(\mathrm{kg} \cdot \mathrm{K})) ; m_{w}-$ mass of water after melting $\left(\mathrm{kg}, m_{w}=m_{i c e}\right) ; \rho_{\text {ice }}$ - density of ice $\left(\mathrm{kg} / \mathrm{m}^{3}\right) ; d$ - cable's diameter $(\mathrm{m}) ; \Delta d_{m}$ - thickness of ice layer, which should be melted $(\mathrm{m})$.

Since the energy, required for heating cable and melting ice, formed by the flow of current through the cable:

$$
W_{w . l}=I_{e f}^{2} \cdot R_{e l} \cdot t_{m e l t},
$$

where: $I_{e f}=\sqrt{I_{m}^{2} \cdot t_{p} / T}$ - effective current value (A); $R_{e l}$ - electric resistance of cable (ohm); $t_{m e l t}-$ time of melting (s); $I_{m}$ - amplitude of current's pulses (A); $t_{p}$ - pulse width (s); $T$ - pulse period (s); $t_{p} / T=\gamma-$ pulse ratio. Therefore, the required parameters of current's pulses can be defined as:

$$
I_{m}=\sqrt{\frac{c_{c} \cdot m_{c} \cdot\left(t_{1}-t_{2}\right)+m_{i . l} \cdot\left(q_{m . i}-c_{i c e} \cdot t_{2}+c_{w} \cdot t_{1}\right)}{R_{e l} \cdot t_{m e l t} \cdot \gamma}} .
$$

So, pulse ratio at the fixed $I_{m}$ should be equal:

$$
\gamma=\frac{c_{c} \cdot m_{c} \cdot\left(t_{1}-t_{2}\right)+m_{i . l} \cdot\left(q_{m . i}-c_{i c e} \cdot t_{2}+c_{w} \cdot t_{1}\right)}{R_{e l} \cdot t_{m e l t} \cdot I_{m}^{2}} .
$$

\section{Ice cylinder fracturing process}

The main factor, providing the breaking of the ice cylinder, formed around power cable, into a few fragments is the presence of bending moments occurring during power cable's oscillations due to the Ampere force. The frequency and amplitude of the cable's oscillations depend on the span length, the power cable's mechanical properties and the parameters of the current pulse flowing through the cable.

As is generally known [7], the bending moment of ice cover (in the form of a plate) may be defined as:

$$
M_{b}=\frac{\rho_{i c e} \cdot g \cdot \hbar \cdot l_{s t}^{2}}{2},
$$


Where: $\hbar$ - the thickness of the ice cover $(\mathrm{m}) ; g-$ free fall acceleration $\left(9.81 \mathrm{~m} / \mathrm{s}^{2}\right) ; l_{s t}-$ half of wave length of ice plate's static deflection (m) (see Fig. 1).

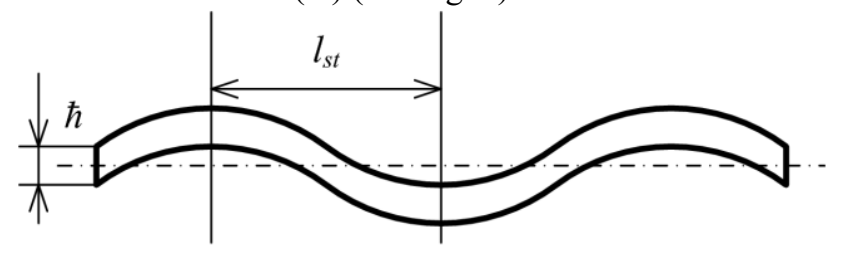

Fig. 1. Ice plate's bending

To simplify the problem solutions we assume that the ice cylinder can be represented as a square cross-section. Then the plates in the top and bottom planes of the cylinder will be bended, and the lateral planes will only be shrinked end stretched. The upper cylinder's plate under the influence of the bending moment will experience compression at the bending point, and the lower - stretching. Assuming that the forces consumed for compression and stretching of the cylinder's lateral plates, substantially less than forces consumed for compression and stretching the upper and lower plates of the cylinder, and the forces of compression and stretching of these plates are the same, the bending moment of the ice cylinder is:

$$
M_{i . c}=\rho_{i c e} \cdot g \cdot \hbar \cdot l_{s t}^{2} .
$$

At a certain limiting value of the bending moment

$$
M_{\text {lim }}=\sigma_{\text {bend }} \cdot \hbar^{2} / 6 \text {, }
$$

where $\sigma_{\text {bend }}$ - ultimate bending strength of ice $\left(\mathrm{N} / \mathrm{m}^{2}\right)$, we can define a length of the fractured ice cylinder element:

$$
l_{i . c}=\sqrt{\frac{\sigma_{\text {bend }} \cdot \hbar}{6 g \cdot \rho_{\text {ice }}}} .
$$

It should be emphasized, that $\sigma_{\text {bend }}$ depends on the temperature, and it rises while the temperature falls. For example, ultimate bending strength of sea ice rises on $50 \%$ while the temperature falls from $-1.2{ }^{\circ} \mathrm{C}$ to $-4{ }^{\circ} \mathrm{C}$.

In the analyzed case, the bending moment will occur at the expense of the electrodynamic effect produced by the Ampere force. At the same time, taking into account the principle of superposition, the bending moment will represent the cumulative effect of two things:

$$
M_{\text {bend }}=M_{F}+M_{I} \cdot F_{I},
$$

where: $M_{F}$ - moment of force, conditioned by the static effect of disturbing force $F(t)=F_{\max } \cdot \sin \theta t ; M_{I} \cdot F_{I}-$ moment component, conditioned by the effect of inertial force; $M_{I}-$ bending moment of unit force; $F_{\max }$ - peak value of the Ampere force; $\theta$ - frequency of electrodynamic influence forced oscillation.

Assuming power transmission wires on the period of the natural oscillations are parallel, the peak value of the Ampere force is determined:

$$
F=\frac{2 \cdot \mu_{0} \cdot I_{1} \cdot I_{2} \cdot l_{p a r}}{4 \cdot \pi \cdot r_{12}}
$$

where: $\mu_{0}$ - permeability of vacuum $\left(4 \pi \cdot 10^{-7} \mathrm{~N} / \mathrm{A}^{2}\right) ; I_{1}, I_{2}-$ amplitudes of current pulses in the wires (A); $r_{12}$ - distance between the wires (m); $l_{p a r}$ - length of the parallel wires (m).

Supposing that the point of the mass of wire and the point of application of the electrodynamic effects are the same, the bending moment can be determined by static load $M_{F}$ and dynamic factor $k_{d y n}:$

$$
M_{\text {bend }}=k_{d y n} \cdot M_{F},
$$


where: $k_{d y n}=1 /\left(1-\theta^{2} / \omega_{0}^{2}\right) ; \omega_{0}$ - wire's free oscillation's circular frequency $\left(\mathrm{s}^{-1}\right)$.

$$
\omega_{0}=(\pi / l) \cdot \sqrt{T_{0} / \mu}
$$

where: $\mu$ - wire's linear density $(\mathrm{kg} / \mathrm{m}) ; T_{0}$ - conductor strain $(\mathrm{N})[8]$.

On the other hand, the static moment $M_{F}$ can be evaluated as the product of the driving force and the $\operatorname{arm} l$, and provided that wire's oscillations are sinusoidal, $l \approx \lambda / 2$, where $\lambda(\mathrm{m})-$ the wavelength of the oscillations.

Thus, when the parameters of oscillations are fixed, we can determine the length of the fractured ice cylinder elements and find a mass of ice to be shaking off.

\section{Process of fractured ice cylinder elements shaking off}

The process of shaking off the fractured ice cylinder elements will occur under the influence of dynamic effect. When wire's oscillations are sinusoidal, the displacement of material point of wire's part is defined as:

$$
x=A \cdot \cos (\omega t+\varphi),
$$

where: $A$ - amplitude of material point's oscillation $(\mathrm{m}) ; \omega$ - frequency of wire's oscillation $\left(\mathrm{s}^{-1}\right) ; \varphi$ - phase shift of oscillations (rad).

The material point's acceleration can be evaluated as:

$$
a=A \cdot \omega^{2} \cdot \cos (\omega t+\varphi+\pi)
$$

and the driving force acting on the oscillating wire section (material point):

$$
F_{d r}=\left(m_{c}+m_{i c e}\right) \cdot A \cdot \omega^{2} \cdot \cos (\omega t+\varphi+\pi) \text {, }
$$

where $m_{\text {ice }}$ - mass of ice cover $(\mathrm{kg})$.

The amplitude of wire's material point's forced oscillation can be estimated by the next expression [9]:

$$
A=h / \sqrt{\omega_{0}^{2}-\omega^{2}-4 \cdot \beta^{2} \cdot \omega^{2}},
$$

Where: $h=F_{d r} /\left(m_{c}+m_{\text {ice }}\right)$ - ratio of driving force's peak value and mass; $\beta$ - oscillation's damping factor.

When $\beta \rightarrow 0, A=h /\left(\omega_{0}^{2}-\omega^{2}\right)$.

Shaking off the fractured ice cylinder element will occur on condition that driving force $F_{d r}$ is greater than the weight of the element, which can be calculated by the expression:

$$
P=g \cdot \rho_{\text {ice }} \cdot l \cdot \pi \cdot \Delta d \cdot(d+\Delta d),
$$

Where: $\Delta d$ - thickness of the ice cylinder $(\mathrm{m})$.

\section{Conclusions}

So, the represented mathematical description of deicing physical processes allows to design a mathematical model of power transmission line's wires deicing by electrodynamic influence. It's possible to research deicing process at the different power line's characteristics, different ice formation conditions and different parameters of electrodynamic influence, on the basis of the model.

This research allows to optimize the parameters of electrodynamic influence's source, to estimate an influence of assumptions on the deicing process's quality and efficiency. As a result, effective control law for the source of electrodynamic influence can be developed.

The reported study was supported by the State Task Funding "Science" of Russian Federation (2.1318.2014). 


\section{References}

1. V.M. Kozin, V.A. Soloviev, D.A. Orlov, S.I. Sukhorukov, K.S. Malih "Method for deicing of power transmission lines" Patent RU 2442256, 2012.

2. V.M. Kozin, D.A. Orlov, V.A. Soloviev, S.I. Sukhorukov "Method for deicing of trolley line and power transmission lines" Deformable solid mechanics applications, № 4, Komsomolsk-naAmure, 2013, pp. 126-138.

3. V.A. Soloviev, S.I. Sukhorukov "Controllable current source for de-icing of power transmission line's wire’s experimental unit", Electrotechnical complexes and control systems, Voronezh, № 4, 2013, pp. 6-10.

4. R.V. Goldstein, V.P. Epifanov "Adhesive strength of ice sedimentation on the metallic constructipn elements", Vestnik Novosibirskogo Gosudarstvennogo Universiteta. Seriya Matematika, Mekhanika, Informatika, Novosibirsk, vol. 12, № 4, 2012.

5. K.Matsumoto, T.Kobayashi "Fundamental study on adhesion of ice to cooling solid surface" International Journal of Refrigeration, 2007. vol. 30, pp. 851-860.

6. E.G. Gologorskij, A.N. Kravtsov, B.M. Uzelkov "Reference book of building and reconstruction of power transmission lines with 0.4-750 kV voltage", NC ENAS, Moscow, 2007.

7. V.V. Bogorodskij, A.V. Gusev "Physics of Ocean", Gidrometeoizdat, Leningrad, 1978.

8. D.R. Merkin "Introduction to torsion fiber's mechanic", Nauka. The main editorial office of physico-mathematical literature, 1980.

9. T.I. Trofimova "Physics course", 2nd ed., High School, Moscow, 1990. 